\title{
Avaliação da implementação da Política Nacional de Saúde Integral à população LGBT em um município da região Sudeste do Brasil
}

\author{
Evaluation of the implementation of the National Comprehensive Health \\ Policy for the LGBT population in a municipality in the Southeast region \\ of Brazil
}

\section{Evaluación de la implementación de la Política Nacional de Salud Integral para la población LGBT en un municipio de la región sudeste de Brasil}

Nilo Plantiko Guimarães ${ }^{1, a}$

niloplangui@gmail.com | https://orcid.org/o0oo-0001-9571-9760

Rafaela Lirio Sotero ${ }^{1, b}$

rafaelaliriosotero@gmail.com | https://orcid.org/0000-0001-8127-6129

João Paulo Cola ${ }^{1, c}$

joaopaulocola@gmail.com | https://orcid.org/o0oo-0003-4972-4686

Suzana Antonio ${ }^{1, d}$

suzananv@hotmail.com | https://orcid.org/oooo-0001-6157-3759

Heletícia Scabelo Galavote ${ }^{1, e}$

heleticiagalavote@yahoo.com.br | https://orcid.org/oooo-0003-4490-6763

${ }^{1}$ Universidade Federal do Espírito Santo. Vitória, ES, Brasil.

a Graduação em Enfermagem pela Universidade Federal do Espírito Santo.

b Especialização em Enfermagem do Trabalho e Saúde Ocupacional pela Universidade Cândido Mendes.

c Mestrado em Saúde Coletiva pela Universidade Federal do Espírito Santo.

d Mestrado em Enfermagem pela Universidade do Estado do Rio de Janeiro.

e Doutorado em Saúde Coletiva pela Universidade Federal do Espírito Santo.

\section{Resumo}

A população LGBT (Lésbicas, Gays, Bissexuais, Travestis e Transexuais), por não se encaixar nos padrões heteronormativos, recebe um tratamento pejorativo e excludente, o que limita o acesso aos serviços de saúde. Este estudo tem como objetivos avaliar a implementação da Política Nacional de Saúde Integral à População LGBT (PNAIPLGBT) na atenção básica de saúde e compreender o conhecimento de enfermeiros da Estratégia Saúde da Família acerca da diversidade sexual e da homofobia. Trata-se de um estudo descritivo, exploratório e de natureza qualitativa. Os participantes relatam ausência ou limitação de conhecimento sobre a PNAIPLGBT. Assim, a falta de conhecimento sobre o público LGBT e o despreparo dos profissionais de saúde para acolher o público em questão resultam na restrição do acesso da população LGBT aos serviços de saúde, o que afeta diretamente na realização da Política Nacional de Atenção Integral à População LGBT.

Palavras-chave: Enfermagem em saúde comunitária; Minorias sexuais e de gênero; Sexualidade; Políticas públicas; Atenção primária à saúde. 


\section{Abstract}

The LGBT population (Lesbian, Gay, Bisexual, Transvestite and Transsexual), since it does not fit the heteronormative patterns, ends up receiving a pejorative and exclusive treatment, which limits access to health services. This study aims to evaluate the implementation of the National Policy on Comprehensive Health for LGBT Population (PNAIPLGBT) in basic health care and to understand the knowledge of nurses in the Family Health Strategy regarding sexual diversity and homophobia. This is a descriptive, exploratory study of a qualitative nature. Participants report absence or limitation of knowledge about PNAIPLGBT. Thus, the lack of knowledge about the LGBT public and the lack of preparation of health professionals to welcome the public in question results in the limitation of LGBT population access to health services, which directly affects the implementation of the National Policy of Comprehensive Attention to Population LGBT.

Keywords: Community health nursing; Sexual and gender minorities; Sexuality; Public policy; Primary health care.

\section{Resumen}

La población LGBT (Lesbianas, Gays, Bisexuales, Travestis y Transexuales) por no encajar en los patrones heteronormativos acaba recibiendo un trato peyorativo y excluyente, lo que limita el acceso a los servicios de salud. Este estudio tiene como objetivos evaluar la implementación de la Política Nacional de Salud Integral a la Población LGBT (PNAIPLGBT) en la atención básica de salud y comprender el conocimiento de enfermeros de la Estrategia Salud de la Familia en lo referente a la diversidad sexual y la homofobia. Se trata de un estudio descriptivo, exploratorio de naturaleza cualitativa. Los participantes reportan ausencia o limitación de conocimiento sobre la PNAIPLGBT. Así, la falta de conocimiento sobre el público LGBT y el despreparo de los profesionales de salud en acoger al público en cuestión, resulta en la limitación del acceso de la población LGBT a los servicios de salud lo que afecta directamente en la implementación de la Política Nacional de Atención Integral a la Población LGBT.

Palabras clave: Enfermería en salud comunitaria; Minorías sexuales y de género; Sexualidad; Política pública; Atención primaria a la salud.

Contribuição dos autores:

Concepção e desenho do estudo: Nilo Plantiko Guimarães, Heletícia Scabelo Galavote.

Aquisição, análise ou interpretação dos dados: Nilo Plantiko Guimarães, Heletícia Scabelo Galavote.

Redação do manuscrito: Nilo Plantiko Guimarães, Rafaela Lirio Sotero, Heletícia Scabelo Galavote.

Revisão crítica do conteúdo intelectual: Nilo Plantiko Guimarães, Rafaela Lirio Sotero, Heletícia Scabelo Galavote, João Paulo Cola, Suzana Antonio.

Declaração de conflito de interesses: não há.

Fontes de financiamento: não há.

Considerações éticas: aprovação de número 2.561 .237 no Comitê de Ética em Pesquisa do Centro Universitário Norte do Espírito Santo - Universidade Federal do Espírito Santo.

Agradecimentos/Contribuições adicionais: não há.

Histórico do artigo: submetido: 31 jan. 2019 | aceito: 11 maio 2020 | publicado: 30 jun. 2020.

Apresentação anterior: não houve.

Licença CC BY-NC atribuição não comercial. Com essa licença é permitido acessar, baixar (download), copiar, imprimir, compartilhar, reutilizar e distribuir os artigos, desde que para uso não comercial e com a citação da fonte, conferindo os devidos créditos de autoria e menção à Reciis. Nesses casos, nenhuma permissão é necessária por parte dos autores ou dos editores. 


\section{Introdução}

De acordo com o sexo biológico, feminino ou masculino, a sociedade é encaminhada a seguir padrões heteronormativos preestabelecidos, que compreendem desde o comportamento, valores e pensamentos a vestimentas e cores, em que homem se relaciona com mulher e macho com fêmea, como uma prática de reprodução humana. Na fase adulta, quando se passa de aprendizes para educadores, dissemina-se a mesma ideia da heteronormatividade ${ }^{1}$.

Habituados com o padrão heteronormativo da sociedade contemporânea, tanto professores quanto materiais educativos, como manuais, livros, folders, pôsteres e almanaques, que são responsáveis pela educação sexual na escola, analisam a questão sexual numa abordagem anato-morfofisiológica ${ }^{2}$.

Esta linha de pensamento já foi problematizada por Foucault em 1993, ao mostrar que o dispositivo da sexualidade na modernidade só pode ser compreendido por meio dos mecanismos de poder e saber que lhes são intrínsecos. Assim, a condição sexual é o resultado de fatores individuais, desejos e experiências e não algo determinado segundo o órgão genital biológico³.

Dessa forma, falar de sexualidade é também se referir à produção dos saberes que a constituem, aos sistemas de poder que regulam suas práticas e às formas pelas quais os indivíduos podem e devem se reconhecer como sujeitos sexuados. Em outras palavras, o sexo heteronormativo não é uno e absoluto, mas sim, "uma construção ideal forçosamente materializada através do tempo3" (p.10).

Segundo o autor, as relações homoafetivas eram respeitadas em tempos remotos, ou por uma imagem de "mistura dos sexos", mas somente a partir do século XVII é que as teorias biológicas da sexualidade e as condições jurídicas forçadamente impostas à sociedade passaram a restringir a livre escolha dos indivíduos incertos ${ }^{3}$.

Toda e qualquer criança, jovem e adulto que não se encaixa nesses moldes da heteronormatividade são marginalizados, excluídos e vítimas de preconceitos. Esse modelo de educação acaba semeando proibições que dão origem a discriminações, prejulgamentos e, consequentemente, à homofobia, lesbofobia e transfobia 4 .

O insucesso da educação sexual e a tendência à prática de discriminação são enraizados, historicamente, como já disse Foucault em 1998, e está direcionada por uma forma de saber desenvolvida graças ao conhecimento médico, ou seja, a organização curricular das escolas de ensino fundamental, médio e de ensino superior que abrange o discurso sobre sexualidade baseando-se no discurso científico médicobiológico e focado na reprodução humana ${ }^{5}$.

A população LGBT (Lésbicas, Gays, Bissexuais, Travestis e Transexuais), por não se encaixar nestes padrões de heteronormatividade, acaba recebendo um tratamento pejorativo, injusto e excludente, o que limita o acesso dessa população aos serviços de saúde ${ }^{6}$.

O Ministério da Saúde, embasado nos princípios assegurados na Constituição Federal de 1988 (CF/88), que garantem a cidadania e dignidade da pessoa humana ${ }^{7}$ e reforçados no objetivo fundamental da República Federativa do Brasil de "promover o bem de todos, sem preconceitos de origem, raça, sexo, cor, idade e quaisquer outras formas de discriminação", lançou no ano de 2010 na $14^{\circ}$ Conferência Nacional de Saúde, a Política de Saúde para o público LGBT, com a intenção de garantir um atendimento da população em qualquer situação, sem discriminação de qualquer natureza ${ }^{8}$.

Considerando que o público LGBT historicamente foi negligenciado, sofreu e ainda sofre preconceitos, e que atualmente necessita de um atendimento que visa à equidade para um acesso de qualidade na assistência de saúde prestada na Atenção Básica, surge a necessidade de conhecer e avaliar o papel do profissional enfermeiro na implementação da política LGBT.

Dessa forma, o presente estudo tem por objetivo geral: analisar o acesso da população LGBT à assistência à saúde na atenção básica, em um município do estado do Espírito Santo (ES); e por objetivos específicos: 
avaliar a implementação da Política Nacional de Saúde Integral à População LGBT na atenção básica à saúde, compreendendo o conhecimento de enfermeiros da Estratégia Saúde da Família (ESF) no tocante à diversidade sexual e à homofobia no referido local.

\section{Estratégia metodológica}

Trata-se de um estudo descritivo, exploratório e de natureza qualitativa. As pesquisas descritivas caracterizam-se frequentemente como estudos que procuram determinar status, opiniões ou projeções futuras nas respostas obtidas. A sua valorização está baseada na premissa de que os problemas podem ser resolvidos e as práticas podem ser melhoradas por meio da descrição e análise de observações objetivas e diretas. As técnicas utilizadas para a obtenção de informações são diversas, destacando-se os questionários, as entrevistas e as observações9.

A pesquisa qualitativa é aquela capaz de incorporar a questão do significado e da intencionalidade como inerentes aos atos, às relações e às estruturas sociais, sendo essas últimas tomadas, tanto no seu advento quanto nas suas transformações, como construções humanas significativas. Assim, a abordagem qualitativa aplica-se ao estudo da história, das relações, das representações, das crenças, das percepções e das opiniões, produto das interpretações que os seres humanos fazem de como vivem, constroem seus artefatos e a si mesmos, sentem e pensam ${ }^{10-11}$.

O estudo foi realizado nas unidades básicas de saúde em um município da região norte do estado do Espírito Santo, situado na região sudeste. É um dos municípios mais antigos do Brasil, com aproximadamente 126.437 habitantes, e conta com 26 equipes de estratégia saúde da família (ESF), sendo 9 com saúde bucal, 2 programas de agentes comunitários de saúde (PACS) nas áreas rurais, contanto com 170 agentes comunitários de saúde e 25 unidades básicas de saúde (UBS) ${ }^{12}$. A escolha do município se deve ao fato de ser o polo da macrorregião Norte de Saúde do estado do Espírito Santo e por ser a sede do Centro Universitário Norte do Espírito Santo da Universidade Federal do Espírito Santo.

Foram convidados a participar da pesquisa dez profissionais com nível superior em enfermagem que compõem as equipes da ESF do município. Os participantes foram selecionados mediante sorteio aleatório das unidades de saúde do município na correlação do atendimento aos critérios de inclusão do estudo, sendo eles: que o profissional integrasse a equipe da ESF por, no mínimo, um ano e aceitasse participar da pesquisa assinando o termo de consentimento livre e esclarecido (TCLE). Foram excluídos da pesquisa profissionais que estavam afastados do serviço ou impossibilitados de falar durante a coleta de dados, profissionais que integravam a equipe da ESF por um período inferior a um ano e profissionais que se recusaram a participar da pesquisa e assinar o TCLE.

A coleta de dados se deu mediante entrevista semiestruturada e observação participante. A entrevista semiestruturada é um processo no qual o entrevistador tem a finalidade de obter informações do entrevistado por meio de um roteiro contendo perguntas previamente elaboradas em torno da problemática em questão ${ }^{13}$. O período da coleta de dados foi de abril a maio de 2018. As entrevistas foram previamente agendadas e realizadas individualmente no local de trabalho em uma sala de escolha do entrevistado onde o mesmo se sentiu confortável. Além de terem sido feitas em um gravador de voz e posteriormente transcritas obedecendo fielmente às falas dos participantes.

A verificação dos dados obtidos foi realizada de acordo com a análise temática de Minayo em que a presença de determinados temas denotou os valores de referência e os modelos de comportamento presentes no discurso. Operacionalmente a análise temática desdobra-se em três etapas: pré-análise, que inclui leitura flutuante, constituição de corpus, formulação de hipóteses e objetivos, em que o pesquisador deve tomar contato exaustivo como o material para conhecer seu conteúdo; exploração do material; tratamento dos resultados obtidos e interpretação ${ }^{14}$. 
O estudo foi desenvolvido conforme os princípios éticos que integram a Resolução 466/2012 do Conselho Nacional de Saúde, com a aprovação de número 2.561.237 no Comitê de Ética em Pesquisa do Centro Universitário Norte do Espírito Santo - Universidade Federal do Espírito Santo. Os atores sociais aqui descritos foram representados por codinomes ENF seguidos pela ordem de participação ENF 01, ENF 02, respectivamente.

\section{Resultados}

\section{Dados de identificação e perfil profissional}

Na Tabela 1 são apresentadas as características sociodemográficas dos profissionais enfermeiros que participaram da entrevista e atuam no município em estudo. Foi possível observar que predominam profissionais do sexo feminino (90\%) com idade média de 30 a 39 anos e que oito dos dez profissionais entrevistados são casados.

Tabela 1 - Identificação dos profissionais enfermeiros das unidades básicas de saúde da família participantes da entrevista, 2018

\begin{tabular}{|l|l|}
\hline Variáveis & N \\
\hline Sexo & \\
\hline Feminino & 9 \\
\hline Masculino & 1 \\
\hline Idade & \\
\hline $19-29$ & 2 \\
$30-39$ & 5 \\
\hline $40-49$ & 3 \\
\hline Estado civil & \\
\hline Solteiro & 2 \\
\hline Casado & 8 \\
\hline Forma de ingresso & \\
\hline Concurso público & 10 \\
\hline Tempo de atuação na UBS & \\
\hline$>1$ ano & 5 \\
\hline$>8$ anos & 3 \\
\hline
\end{tabular}

N Total: 10

Fonte: Os autores, 2018.

Os enfermeiros participantes da pesquisa ingressaram em sua totalidade por meio de concurso público e atuam na ESF há mais de um ano. Com a finalidade de adquirir qualificação e perfis diferenciados para atuar na atenção básica, oito dos 10 profissionais entrevistados realizaram pós-graduação, como é possível observar na Tabela 2, alguns voltados para a saúde da família, entre outras áreas, como enfermagem do trabalho, graves e críticos, cardiologia e médico-cirúrgica. Dois dos enfermeiros não realizaram pósgraduação, e um dos 10 participantes obteve o título de mestre em políticas públicas. 
Tabela 2 - Perfil de formação dos profissionais entrevistados que atuam nas UBS em um município do norte do Espírito Santo/Brasil, 2018

\begin{tabular}{ll} 
Variáveis & N \\
Curso de pós-graduação completo & 8 \\
Sim & 2 \\
Não & \\
Área do curso de pós-graduação completo & 2 \\
Educação em saúde & 3 \\
Atenção Primária à Saúde & 3 \\
Enfermagem do trabalho & 5 \\
Saúde da família & 1 \\
Graves e críticos & 1 \\
Cardiologia & 1 \\
Médico-cirúrgica & \\
Mestrado & 1 \\
Sim & 9 \\
Não & \\
\hline
\end{tabular}

N total: 10

Fonte: Os autores, 2018.

\section{Discussão}

\section{Formação acadêmica}

O conhecimento dos profissionais sobre identidade de gênero e orientação sexual foi ofertado em sua maioria durante a formação acadêmica principalmente durante a abordagem da temática de infecções sexualmente transmissíveis. Quatro dos profissionais entrevistados não receberam orientações sobre o tema durante a graduação, e um profissional teve o tema abordado na sala de aula por meio de discussão de artigos.

Na contemporaneidade, é possível observar um significativo movimento da sexualidade sendo tema de debate no ensino superior. Entre os espaços de discussão da sexualidade, nesse nível de ensino, estão: cursos de extensão, palestras, eventos, atuação dos grupos de pesquisa com o desenvolvimento de atividades e ações para repensar as questões que envolvem essa temática. Dentre outras estratégias, esses meios têm possibilitado algumas discussões da sexualidade, identidade de gênero e saúde da população LGBT nas universidades. No entanto, se observa a incidência do assunto em disciplinas que discutem as questões de sexualidade sendo ofertadas em algumas universidades federais do Brasil na modalidade obrigatória e, em outras, como disciplinas optativas ${ }^{15}$.

Ainda segundo os autores, a discussão sobre o tema foi proposta pelo Ministério da Educação (MEC) por meio da Secretaria de Educação Continuada, Alfabetização, Diversidade e Inclusão (SECADI) com discussões pelo eixo transversal Orientação Sexual presente nos Parâmetros Curriculares Nacionais (PCN) que emergem na década de 1990; além do aumento da violência sexista, racial e homofóbica; as múltiplas identidades que têm se apresentado nas escolas, universidades, na rede de saúde como os/as travestis e 
os/as transexuais; e a utilização do nome social ${ }^{15}$. No entanto, ENF 01 aponta que mesmo sendo parte do currículo proposto pelo Ministério da Educação desde a década de 90, muitas universidades não adequaram seu currículo para abordar o tema da diversidade sexual.

Na minha graduação, há 20 anos atrás, não abordava isso não. (ENF 01).

Colocar em pauta obrigatória a discussão sobre o tema nas instituições de ensino superior auxilia na desconstrução de preconceitos historicamente disseminados nas sociedades ocidentais que contribuem para consolidar o despreparo dos profissionais da saúde quando em contato com a diversidade sexual, visto que, ao longo de sua formação, não são obrigatoriamente preparados e estimulados a discutir o tema de maneira aberta e sem preconceitos. Essa deficiência prejudica a relação profissional-usuário, pois inibe a livre expressão de lésbicas, gays, bissexuais, transexuais e travestis, ao falar com esses especialistas sobre sua orientação sexual e, com isso, acaba por criar barreiras nas relações de produção do cuidado ${ }^{16}$. ENF 5 , 2 e 9 demonstram em suas falas a estigmatização do público LGBT em relação às infecções sexualmente transmissíveis, ensinamentos transmitidos aos profissionais durante a formação acadêmica.

Quando fala sobre DST acaba falando sobre isso também (se referindo ao público LGBT) [...]. (ENF: 05, 02, 09).

O estigma, preconceito e correlação do público LGBT como o principal transmissor de Infecções sexualmente transmissíveis ganha força nos anos 80, com o descobrimento do HIV/AIDS, uma infecção/ doença que afeta o sistema imunológico em especifico as células CD4 e CD8 de pessoas anteriormente saudáveis, levando ou não a infecção por doenças oportunistas e possível morte de homossexuais masculinos. A eclosão da doença alcança visibilidade mundial, e surgem expressões como Síndrome da Ira de Deus, 'peste gay', 'câncer gay', expressões utilizadas, inclusive, por profissionais de saúde na época. Passavam a ideia de que a doença seria uma espécie de castigo divino para pessoas cujo comportamento sexual não condizia com os dogmas cristãos. Assim, além de sofrerem com os terríveis danos físicos visíveis acarretados pela doença, as vítimas da AIDS tiveram que lidar, também, com a culpabilização lançada sobre elas. Posteriormente a síndrome se manifestou em usuários de drogas injetáveis, hemofílicos e também em heterossexuais, caindo por terra o câncer $g a y^{16}$. A culpabilização e associação do público LGBT como disseminadores de IST’s por parte dos profissionais de saúde se caracteriza como violência e discriminação, que resultam em barreiras de acesso para essas populações ${ }^{17}$.

\section{Conhecimentos gerais sobre o público LGBT}

A orientação sexual de indivíduos que se consideram homossexuais caracteriza-se por uma pessoa que se sente atraída sexualmente, emocionalmente ou afetivamente por pessoas do mesmo sexo/gênero. No presente estudo, os agentes pesquisados confundiam esses parâmetros com a identidade de gênero, que se apresenta como uma experiência interna e individual do gênero de cada pessoa, que pode ou não corresponder ao sexo atribuído no nascimento, incluindo o senso pessoal do corpo envolvendo a modificação da aparência ou função corporal por meios cirúrgicos e outras expressões de gênero como vestimenta e modo de falar ${ }^{19}$. Os profissionais entrevistados têm dificuldades em dissociar orientação sexual de identidade de gênero, como é possível observar na fala do profissional ENF 01. 
[...] há um mês eu atendi uma pessoa que todas as características eram de um homossexual, [...] tanto que unha, cabelo, fala, [...] estava vestido praticamente de mulher. (ENF 01).

Durante a produção de dados, em meio a momentos de silêncio, emergiram conceitos simplórios e limitados às letras da sigla LGBT. Era evidente a dificuldade dos profissionais em discursar sobre o público LGBT, demonstrando o autorreconhecimento da escassez de conteúdo envolvendo questões de gênero, e tendendo à normatização de expressões da sexualidade.

Mesmo com a falta de conhecimento e o acúmulo de conteúdo sobre o tema, os entrevistados demonstram manter os preconceitos disseminados ao longo da história, julgamentos esses de cunho moral e religioso. Foi deixado de lado o objetivo de oferecer uma assistência ética, sem juízo de valor e visando à qualidade do serviço prestado aos usuários que não se encaixam nos padrões da heteronormatividade, para promover a democracia social e laicidade do Estado ${ }^{19}$. Emerge em suas falas novamente a correlação entre o público LGBT e IST's.

[...] apesar de eu ter uma formação religiosa, bastante, como eu diria: arcaica, eu consigo separar muito bem isso. Então não tenho nenhum tipo de preconceito, atendo essa clientela, faço testes rápidos, dou orientação, então pra mim é um paciente como qualquer outro. (ENFo4).

A sexualidade é uma necessidade humana básica que deve ser abordada juntamente com outros aspectos relevantes da vida. Cabe aos profissionais da saúde e da educação contribuir para sanar dificuldades relacionadas ao tema da sexualidade, responsabilidade reafirmada na política nacional de saúde LGBT que em seu art. $4^{\circ}$, inciso $\mathrm{V}$, visa definir estratégias que promovam a atenção e o cuidado especial com adolescentes lésbicas, gays, bissexuais, travestis e transexuais, garantindo sua saúde mental, assim como acolhimento e apoio ${ }^{20}$.

\section{Conhecimentos sobre a política LGBT}

Desde a $12^{\text {a }}$ Conferência Nacional de Saúde, os direitos da população LGBT vêm sendo pautados pelos princípios do SUS, e em 2007, na $13^{\text {a }}$ Conferência Nacional de Saúde, a orientação sexual e a identidade de gênero foram incluídas na análise da determinação social da saúde. Algumas recomendações foram feitas com o objetivo de reduzir as desigualdades que o público LGBT vem sofrendo ao longo dos anos nesses serviços. Entre as recomendações podemos destacar a sensibilização dos profissionais a respeito dos direitos de LGBT, com inclusão do tema da livre expressão sexual na política de educação permanente no SUS; a inclusão dos quesitos de identidade de gênero e de orientação sexual nos formulários, prontuários e sistemas de informação em saúde; a ampliação da participação dos movimentos sociais LGBT nos conselhos de saúde; o incentivo à produção de pesquisas científicas, inovações tecnológicas e compartilhamento dos avanços terapêuticos; a garantia dos direitos sexuais e reprodutivos e o respeito ao direito à intimidade e à individualidade; o estabelecimento de normas e protocolos de atendimento específicos para as lésbicas e travestis; o aprimoramento do Processo Transsexualizador; a implementação do protocolo de atenção contra a violência considerando a identidade de gênero e a orientação sexual ${ }^{21}$.

Após quatro anos da $13^{\circ}$ Conferência Nacional de Saúde, o poder público nas suas três esferas de governo, visando assegurar, prevenir, proteger, reparar e promover políticas públicas que busquem a afirmação dos direitos humanos para toda a sociedade livre de preconceito, discriminação, intolerância ou violência motivada por aspectos ligados a origem, raça, sexo, cor, idade, crença religiosa, condição social ou orientação sexual, lança por meio do Ministério da Saúde a Política Nacional de Saúde LGBT. Considerada como um divisor de águas para as políticas públicas de saúde no Brasil, é um marco histórico 
de reconhecimento das demandas desta população em condição de vulnerabilidade, que diminui o caráter marginalizado dos serviços de saúde vistos por décadas ${ }^{22}$.

Quando questionados sobre os conhecimentos adquiridos a respeito da Política Nacional de Saúde Integral e como classificavam seu conhecimento sobre a política, 70\% dos entrevistados o classificaram como nulos, dando respostas rápidas e objetivas, como:

Não conheço. (ENF 02, 04, 06, 07, 08, 09, 10).

[...] Pequeno. O que eu conheço da política, é a questão do direito ao nome social, eu não sei direito como se denomina. A questão do nome social, dos direitos que tem ser chamado pelo nome, de ser tratado como prefere, o que eu sei é mais isso, não sei se tem mais alguma outra coisa mais específica. (ENF 01).

[...] garante a eles uma saúde integral. Conheço muito pouco, nunca li ela, mas sei que garante a eles pelo pouco que vi e de uma forma humana e sem discriminação. (ENF 03).

Pouco. O que eu conheço é que eles têm direito a assistência, podem ser chamados pelo nome social, devem ser chamados pelo nome social, que eles têm direito a todo tipo de orientação, todo tipo de atendimento da unidade de saúde, como outra pessoa, sem discriminação, [...]. (ENF 05).

Alguns dos profissionais em estudo alegam nunca ter lido a política em questão, mas todos eles demonstraram preocupação em realizar um acolhimento sem discriminação e preconceito, respeitando as individualidades de cada usuário, como é o exemplo de diversos profissionais entrevistados que mencionaram várias vezes o uso do nome social.

\section{Respeito ao nome social}

A presença do campo destinado ao nome social nos documentos e prontuários da saúde, bem como o respeito dos profissionais de saúde para com os clientes ao adotar o nome de escolha do usuário em seu atendimento, impede que o constrangimento limite o acesso aos serviços de saúde. A garantia do uso do nome social reafirma o compromisso de universalidade e equidade do SUS, descaracterizando a violação de direitos no âmbito institucional, além de estimular o respeito às diversidades. Entretanto, o cumprimento do uso do nome social de travestis e transexuais depende do bom senso dos profissionais, em se despir de dogmas e preconceitos ${ }^{1}$.

Os entrevistados em sua maioria demonstram ser contrários aos preconceitos historicamente disseminados, inclusive estimulando outros funcionários da UBS a cumprirem as leis que abordam o nome social, contribuindo para a efetivação da relação profissional-usuário.

Sim. Se a pessoa se identifica. (ENF 01).

Sim. Sempre que atendemos sim. (ENFo3). 


\section{[...] mas nesse treinamento que eu falei que participei (se referindo à palestra do grupo trans em ação)} a recepcionista também participou, e a gente já é orientado a chamar o paciente e perguntar como ele gostaria de ser chamado, mas até o momento a gente nunca passou por isso não. (ENFo4).

Sim se elas quiserem sim. Inclusive se elas quiserem a gente anota o nome social no prontuário. (ENFO5).

Eu chamo as pessoas pelo nome que elas gostam de ser chamadas (ENFo7).

Infelizmente foi possível identificar em uma das falas o descuido com esta ferramenta para humanização da assistência, que visa ao acolhimento e à promoção do acesso à saúde por meio do nome social. Alguns profissionais apegados ao nome de batismo deixam de exercer o direito dos clientes em serem chamados pelo nome social ou apelido.

Chamo pelo nome do documento e às vezes eu pergunto se tem algum apelido. (ENFog).

O não uso do nome social descrito na fala anterior leva a uma cascata de constrangimentos, que interfere na prestação do cuidado. Uma vez rompido o princípio da confiança, torna-se impossível a preservação da relação nos mesmos moldes que fora iniciado, até porque a confiança dessa relação influi diretamente na recuperação do paciente ${ }^{23}$.

[...] então eu fiquei meio constrangida por isso, porque, ele estava vestido de mulher e eu vou chamar de homem, parece que eu estava agredindo ele. (ENF 01).

\section{Notificações de violência}

A notificação mais utilizada pelos enfermeiros entrevistados é referente à agressão a mulher doméstica, notificações isoladas referentes à violência contra a criança e suicídio foram realizadas em determinada ESF. Um enfermeiro usou a ficha de notificação, mas não se recordou o motivo, e um dos 10 enfermeiros notificados teve conhecimento de que um cliente do distrito sanitário em que atua foi notificado em outro nível de atenção. Em um tópico especifico, em sua totalidade, os enfermeiros alegam nunca ter notificado agressões por LGBTfobia.

Em outubro de 2014, uma nova versão da Ficha de Notificação Individual de Violência Interpessoal/ Autoprovocada foi lançada pela Secretaria de Vigilância em Saúde no Sistema de Informação de Agravos de Notificação (SINAN). Denominada SINAN 5.0, alguns campos foram incluídos como o campo 31 - nome social; campo 34 - orientação sexual; campo 35 - identidade de gênero; campo 53 - essa violência foi motivada por; e o campo 62 - ciclo de vida do provável autor da agressão. As alterações na ficha buscam atender ao disposto na Política Nacional de Saúde Integral de Lésbicas, Gays, Bissexuais, Travestis e Transexuais, ampliando as causas e possibilidades de notificação, incorporando as violências por motivos de homofobia, lesbofobia e transfobia ${ }^{17}$.

Após a atualização do SINAN, segundo o último relatório de Violência Homofóbica no Brasil realizado pelo Grupo Gay da Bahia (GGB), 343 LGBT's foram assassinados no Brasil em 2016. A cada 25 horas um LGBT é assassinado vítima da LGBTfobia, o que faz do Brasil o campeão mundial de crimes contra as 
minorias sexuais. No ano de 2016 houve mais mortes de homossexuais no Brasil do que nos 13 países do Oriente Médio e África, onde há pena de morte contra os LGBT ${ }^{24}$.

Com a tomada de conhecimento sobre a atualização da ficha SINAN pelos profissionais de saúde, novos casos são notificados a cada dia. Em 2017 um novo relatório sobre mortes de LGBT foi lançado mostrando que a cada 19 horas uma nova vítima de LGBTfobia é notificada, totalizando 445 mortes ao ano ${ }^{24}$.

Sobre o atendimento a alguma vítima de violência verbal ou física motivada por homofobia, lesbofobia e transfobia, 100\% dos profissionais apontam nunca ter feito o referido atendimento. Eles também registram a dificuldade que sentem por parte do público LGBT em frequentar as UBS's, sem, no entanto, reconhecerem a possível correlação da ausência de participação do público com a discriminação e exclusão no processo saúde/doença.

Não (referente a atender vítimas de LGBTfobia) É um público também, muito difícil de aparecer, um público que fica muito escondido. [...] Eu to atendendo mais, estão aparecendo mais, mas é um público ainda muito escondido eu acho, [...] Eles se mostram muito para outras coisas, com a saúde principalmente eles têm certo receio. [...] Eles não vêm. (ENF2).

Não. O máximo que eu já tive de atendimento foi para outras demandas como de mulheres lésbicas procurando anticoncepcional pra cortar o período menstrual, já teve procurando também e testagem rápida de HIV e sífilis. (ENFo7).

É preocupante a ausência de travestis e transexuais nos serviços de atenção básica de saúde, que são vistos como a porta de entrada do SUS e considerados o maior local de permanência do usuário. Há uma segregação desse grupo social para serviços específicos, em geral nos centros especializados no processo transsexualizador, por serem locais em que há profissionais capacitados para lidar com as questões de identidade de gênero, limitando o acesso às atividades de promoção e proteção em saúde integral desses indivíduos nas demais instâncias do sistemaํ.

\section{A militância LGBT na garantia de direitos e na atuação da educação permanente}

Ao longo do tempo, as lutas e as manifestações organizadas pelo movimento LGBT em todos os estados brasileiros sensibilizaram comunicadores e agregaram aliados. Porém, ainda existe um longo caminho a ser percorrido pelo movimento para garantir uma transmissão de informações com maior qualidade e comprometimento com as causas sociais ${ }^{18}$.

Eu acho que muita política aconteceu pelo protagonismo LGBT, eu olho admirada e penso que outras políticas poderiam avançar tão quanto tem avançado a política LGBT. (ENF 10).

Neste estudo, a participação social do público LGBT aparece como um requisito para o avanço das conquistas de direitos. Ela deve estar presente nos processos cotidianos de gestão do SUS, sendo garantida por meio das leis orgânicas (Lei 8080/90 e Lei 8142/90) e também tem de ser estimulada pela Política Nacional de Atenção Integral à Saúde LGBT, que visa em seu plano operativo à participação das representações destas populações nos conselhos estaduais e municipais de saúde e em outros espaços de gestão participativa ${ }^{17}$.

A participação social aparece na fala do ENFo4, em que um grupo da militância LGBT denominado ‘TRANS em ação’ percorreu as unidades de saúde oferecendo uma educação permanente para todos os 
funcionários das UBS. Tal atitude da população LGBT demonstra não só a atuação da demanda social, mas o eixo 3 da educação permanente e educação popular em saúde com foco na população LGBT sendo colocado em prática pela própria população, demonstrando o desejo de ser incluída e tratada com respeito nos espaços de saúde ${ }^{17}$.

\section{Conclusão}

Por meio da militância LGBT, avanços em programas e políticas públicas foram conquistados assegurando os direitos à população LGBT. Lançada em 2011, a Política Nacional de Saúde Integral de Lésbicas, Gays, Bissexuais, Travestis e Transexuais ainda não tomou notoriedade entre os profissionais enfermeiros que participaram do presente estudo, levando, assim, à não implementação desejada da PNAIPLGBT no município.

Analisando os discursos com o objetivo de compreender o conhecimento de enfermeiros que participaram da pesquisa, no tocante à diversidade sexual e à homofobia, destaca-se a falta de estímulo em estudar sobre o tema iniciado no processo de formação acadêmica, a qual demonstra limitar o conhecimento sobre a população LGBT a temas ligados a infecções sexualmente transmissíveis, reforçando a estigmatização do público. A falta de abrangência sobre assuntos relacionados ao público em questão leva à formação de profissionais sem preparo algum para lidar com as demandas específicas da população LGBT, principalmente referente ao processo transsexualizador na $\mathrm{AB}$. Tal processo, por ser a porta de entrada do SUS, deve obrigatoriamente realizar o acolhimento envolvendo uma relação cidadã e humanizada de escuta qualificada, visando à adequação do serviço às necessidades dos usuários. No entanto, este acolhimento se demostra limitado, uma vez que os enfermeiros entrevistados, quando questionados acerca dos conhecimentos gerais sobre o público LGBT, demonstraram constrangimento ao falar sobre o assunto durante a produção de dados e se limitaram a pronunciar apenas o significado das letras. Contudo, a sigla possui um vasto significado associado a anos de exclusão social, constrangimento e limitação em abordar o tema que afetou diretamente a realização da pesquisa.

Além da falta de conhecimento sobre o público LGBT, outro ponto demonstra limitar o acesso do público em questão aos serviços de saúde. Percebe-se nas falas que a intenção de respeito ao nome social é grande, mas a utilização da ferramenta se demostra restrita, uma vez que os profissionais no cotidiano de trabalho se concentram no nome de registro. A não utilização da ferramenta de forma correta leva a uma cascata de constrangimentos que interferem na construção do vínculo enfermeiro/usuário, relação esta que, quanto mais solidificada e construída na base da confiança e do respeito às especificidades de gênero, melhor interfere de forma positiva na prestação de cuidados, colocando assim a ausência do público LGBT nas ESF, pautada no texto, como algo pregresso.

O presente estudo evidenciou que no campo da educação permanente nada foi realizado por parte da gestão do município, mas vale destacar a militância LGBT atuando fortemente na participação social, oferecendo palestras e esclarecendo como gostam de ser tratados, com a intenção de fortalecer o vínculo com os serviços de $\mathrm{AB}$. É preciso aprofundar o conhecimento dos profissionais de saúde sobre o público, visando à reafirmação da garantia de direitos como usuários do SUS com base nos princípios da universalidade, integralidade e equidade.

É necessária a ampliação do conhecimento sobre o tema, principalmente, sobre as diferentes identidades de gênero e orientações sexuais, a fim de garantir ao enfermeiro ferramentas de trabalho que propiciem o acesso integral da população LGBT aos serviços de saúde em um processo efetivo de implementação da PNAIPLGBT no município. 
Ressalta-se que os achados deste estudo descrevem a realidade do município selecionado para a pesquisa, considerando que o contexto sociocultural daquele local, ou mesmo da região, pode influenciar os resultados, que não podem ser generalizados.

\section{Referências}

1. Silva GWS, Sena RCF, Cassiano AN, Sobreira MVS, Miranda FAN. Diversidade sexual e homofobia: o conhecimento de enfermeiros da estratégia saúde da família. Cuidado é fundamental [Internet]. 2018 jan.-mar. [citado em 2019 jan. 18];8(1):3725-39. Disponível em: http://www.seer.unirio.br/index.php/ cuidadofundamental/article/view/3942/pdf 1782.

2. Ribeiro PRC, Souza DO. Falando com professores das séries iniciais do ensino fundamental sobre sexualidade na sala de aula: a presença do discurso biológico. Rev Enseñanza de las Ciencias, 2003;21(1):67-75.

3. Foucault M. História da sexualidade I. A vontade de saber. 13. ed. Rio de Janeiro: Graal; 1993.

4. Souza EJ, Silva JP, Santos C. Homofobia na escola: as representações de educadores/as [Internet]. Periódicos Eletrônicos em Psicologia. 2015 [citado em 2019 jan. 18];23(3):635-47. Disponível em: http://pepsic.bvsalud.org/scielo.php?script=sci arttext\&pid=S1413-389X2015000300009.

5. Carvalho FA: Educação sexual: Conflito entre saberes biológicos e culturais. In: Anais do $6^{\circ}$ Encontro Nacional de Pesquisas em Ciências; 2007 nov./dez., Florianópolis (SC): UFSC; 2008.

6. Albuquerque GA, Garcia CL, Alves MJH, Queiroz CMHT, Adami F. Homossexualidade e o direito à saúde: um desafio para as políticas públicas de saúde no Brasil. Saúde em Debate [Internet]. 2013 [citado em 2019 jan. 18];37(98):516-24. Disponível em: https://www.scielo.br/scielo.php?script=sci abstract\&pid=S0103-11042013000300015\&lng=es\&nrm=iso\&tlng=pt.

7. Constituição da República Federativa do Brasil: 1988. Brasília (DF): Centro Gráfico do Senado Federal; 1988.

8. Laurentino ACN. Políticas Públicas de saúde para a população LGBT: da criação do SUS à implementação da Política Nacional de Saúde Integral de LGBT [dissertação]. Rio de Janeiro: Fundação Oswaldo Cruz; 2015.

9. Thomas JR, Nelson JK, Stephen JS. Research methods in physical activity. 7. ed. Champaign: Human Kinetics; 2015.

10. Bardin L. Análise de conteúdo. Lisboa: Edições 70 Ltda; 2015.

11. Fontanella BJB, Ricas J, Turato ER. Amostragem por saturação em pesquisas qualitativas em saúde: contribuições teóricas. Cad. Saúde Pública [Internet]. 2008 jan. [citado 2019 jan. 19];24(1):17-27. Disponível em: http://www.scielo.br/scielo.php?script=sci arttext\&pid=S0102-311X2008000100003.

12. Prefeitura Municipal de São Mateus. Linha do tempo, Atenção Básica em São Mateus-ES. [Internet]. São Mateus, ES; 2017. [citado em 2019 jan. 19]. Disponível em: http:// http://saomateus.es.gov.br/ secretaria/saude.

13. Haguette TMF. Metodologias qualitativas na sociologia. 14. ed. Petrópolis: Vozes; 2013.

14. Minayo MCS. O desafio do conhecimento: Pesquisa qualitativa em saúde. 8. ed. São Paulo: Hucitec; 2004.

15. Rizza JL, Ribeiro PRC, Mota MRA. Disciplinas que discutem sexualidade nos currículos do Ensino Superior brasileiro: produzindo um diagnóstico da situação atual. Rev Linhas. 2016;17(34):197-224.

16. Lopes CR. A epidemia mudou, e o mundo também. Radis, Comunicação e Saúde, 2005;1(40):10-16.

17. Ministério da saúde (BR). Gays, Lésbicas, Bissexuais, Travestis e Transexuais [Internet]. 2017. [citado em 2019 jan. 19]. Disponível em: http://www.saude.gov.br/component/content/article/\%2041380-gayslesbicasbissexuais-\%20travestis-e-transexuais.

18. Associação Brasileira de Lésbicas, Gays, Bissexuais, Travestis e Transexuais. Manual de comunicação LGBT [Internet]. [S.I]: Editora Ltda; 2010. [citado em 2019 jan. 19]. Disponível em: https://unaids.org. br/wp-content/uploads/2015/09/Manual-de-Comunica\%C3\%A7\%C3\%A3o-LGBT.pdf. 
19. Freitas GF, Oguisso T, Fernandes MFP. Fundamentos éticos e morais na prática de enfermagem. Enfermagem em Foco [Internet]. 2010 [citado em 2019 jan. 19];1(3):104-8. Disponível em: http:// biblioteca.cofen.gov.br/wp-content/uploads/2015/11/Fundamentos-eticos-e-morais-na-pratica-deenfermagem.pdf.

20. Ministério da Saúde (BR). Política Nacional de Saúde Integral de Lésbicas, Gays, Bissexuais, Travestis e Transexuais. [Internet]. Brasília: Editora MS; 2013. [citado em 2019 jan. 19]. Disponível em: http:// bvsms.saude.gov.br/bvs/publicacoes/politica nacional saude lesbicas gays.pdf.

21. Ministério da Saúde (BR). Relatório Final da 13a Conferência Nacional de Saúde: Saúde e Qualidade de vida: políticas de estado e desenvolvimento [Internet]. Brasília: Editora MS; 2009. [citado em 2019 jan. 19]. Disponível em: http://bvsms.saude.gov.br/bvs/publicacoes/conferencia nacional saude.pdf.

22. Souza MBCA, Helal DH. Política nacional de saúde integral de lésbicas, gays, bissexuais, travestis e transexuais: análise descritiva e utilização de dados secundários para pesquisa e prática. Bagoas [Internet]. 2015 [citado em 2019 jan.19];9(13):221-52. Disponível em: https://periodicos.ufrn.br/ bagoas/article/view/9656.

23. Palma A. A recusa no atendimento na relação médico e paciente. [Internet]. 2015. [citado em 2019 jan. 19]. Disponível em: https://aryannepalma.jusbrasil.com.br/artigos/254197221/a-recusa-no-atendimentona-relacao-medico-e-paciente.

24. Grupo Gay da Bahia. Assassinato de LGBT no Brasil: Relatório 2017 [Internet]. Salvador. 2017. [citado em 2019 jan. 19]. Disponível em: https://homofobiamata.files.wordpress.com/ 2017/12/relatorio-2081. pdf. 